\title{
Conductive Layers Based on Silver Nanowires by Spray Coating Process
}

\section{JUNAIDI ${ }^{1,2 *}$, NUR ASRIYANI ${ }^{1}$, SIMON SEMBIRING ${ }^{1}$, POSMAN MANURUNG ${ }^{1}$, SUTOPO HADI ${ }^{3 *}$}

${ }^{1}$ Department of Physics, Faculty of Mathematics and Natural Sciences, Universitas Lampung, Bandar Lampung, Indonesia 35145

${ }^{2}$ Instrumentation Research Group, Department of Physics, Faculty of Mathematics and Natural Sciences, Universitas Lampung, Bandar Lampung, Indonesia 35145

${ }^{3}$ Department of Chemistry, Faculty of Mathematics and Natural Sciences, Universitas Lampung, Bandar Lampung, Indonesia 35145

Abstract: In this research, a thin film of silver nanowires $(\mathrm{AgNWs})$ is made by varying the number of layers onto a polycarbonate substrate using a spray coating process. AgNWs were obtained via the polyol method using silver nitrate $\left(\mathrm{AgNO}_{3}\right)$ as rare materials, Polyvinyl pyrrolidone (PVP) as a reducing agent and ethylene glycol (EG) as a solvent. The coating material used is AgNWs solution with a concentration of $10 \%$ in ethanol, which has a diameter and length of $176.13 \mathrm{~nm}$ and $28.58 \mu \mathrm{m}$,

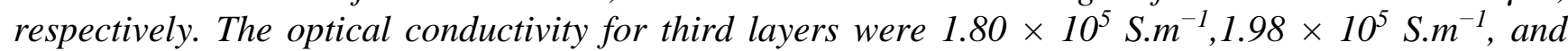
$2.32 \times 10^{5} \mathrm{~S} . \mathrm{m}^{-1}$ by the gap energy of $3.84 \mathrm{eV}, 3.81 \mathrm{eV}$, and $3.79 \mathrm{eV}$ at a wavelength of $550 \mathrm{~nm}$. The greater the number of layers, the higher the optical conductivity. The smaller energy gap indicates that the material absorbs more energy, so the absorbance value is higher. The sheet resistance of AgNWs thin films in variations of each layer was $119.2 \Omega . s q^{-1}, 20.6 \Omega . s q^{-1}$ and $4.98 \Omega . s q^{-1}$. The lower the layer resistance, the higher the density of AgNWs and the thicker the layer. Based on the SEM images by cross-section technique, the thickness of AgNWs thin films obtained by $44.244 \mu \mathrm{m}, 69.126 \mu \mathrm{m}$, and $100.028 \mu \mathrm{m}$ for each layer. AgNWs thin films could be used as transparent conductive electrodes for optoelectronic applications.

Keywords: nanomaterial, silver nanowires, electrodes, thin-film, spray coating

\section{Introduction}

Transparent conductive electrodes (TCEs) are of concern to researchers and the industry because of the increasing need to produce organic light-emitting diodes (OLEDs), solar cells, electronic components, and touch screens in recent years [1-3]. One of the most frequently used TCEs is indium tin oxide (ITO) [4,5]. The main use of ITO is as a transparent conductive thin film used in electronic devices.

ITO has the advantages of high transmittance (T> 90\% at wavelength $550 \mathrm{~nm}$ ) and low resistance (Rs $=10-30 \Omega \cdot \mathrm{sq}^{-1}[4,5]$. In addition to having advantages, ITO also has shortcomings, which are expensive because of indium's limited availability. The synthesis process requires high temperature and high vacuum to control doping thickness and concentration. ITO also has ceramic properties; it is inflexible and fragile [6-8] because it wears and cracks easily when used, has a high refractive index so it is not suitable for touch screen applications $[9,10]$.

Many researchers are trying to solve problems related to transparent ITO electrodes, such as making flexible mechanical electrodes using polyethylene terephthalate (PET) substrates as well as various ratio elements carried out to improve the layers' mechanical properties [7]. However, this approach not only increases production costs but also reduces optical and electrical performance. Therefore, many researchers have tried to find alternative materials to replace ITO with materials that are better than ITO [9].

*email: junaidi.1982@fmipa.unila.ac.id; sutopo.hadi@fmipa.unila.ac.id 
Alternative materials that can be used as substitutes for ITO include carbon nanotubes (CNTs) [10], graphene [11], and metal nanowires (NWs) [12-17]. Carbon nanotubes have good transmittance of up to $97 \%$. However, it has very high resistance around 200 to $3000 \Omega . \mathrm{sq}^{-1}$ [10]. Graphene films show transmittance of $90 \%$ and high resistance of $125 \Omega . \mathrm{sq}^{-1}$. The process of synthesizing graphene films requires very high temperatures up to $1000^{\circ} \mathrm{C}$, so it is expensive [11].

Metal NWs have advantages over other materials in terms of conductivity, flexibility [14], and ease of synthesizing at low temperatures [12]. The resulting transmittance can reach $90 \%$ and the resistance is around $\Omega . \mathrm{sq}^{-1}$. The conductivity and transmittance produced are similar to ITO, making it suitable for transparent electrode applications [15]. Copper nanowires (CuNWs) and silver nanowires (AgNWs) are commonly used. CuNWs layer has almost the same conductivity as AgNWs and the synthesis process is cheaper. However, CuNWs have instability in the air because they react easily with oxygen, so AgNWs are chosen as an alternative material in the manufacture of TCEs [16].

TCEs with AgNWs can be made using various techniques such as spray coating [13], Mayer-rod coating [17], spin coating [18], and dip coating [19]. Spin coating is a easy and fast technique, but it shows the results of non-homogeneous AgNWs coating. The resulting resistance and transmittance are $20 \Omega . \mathrm{sq}^{-1}$ and $77 \%$, respectively [18]. The dip coating technique is done by dipping the substrate into the coating solution. This technique requires a lot of coating material, and the coating process takes a long time. The resulting resistance and transmittance are $100 \Omega . \mathrm{sq}^{-1}$ and $90 \%$, respectively [19].

The Mayer-rod coating technique is a very simple and compatible method by rolling the Mayer rod over the substrate [20]. However, this technique depends on the coating material's viscosity and can work well on materials that have low viscosity. The resistance and transmittance of the resulting layers are $12.1 \Omega . \mathrm{sq}^{-1}$ and $70.1 \%$, respectively [21].

Based on some coating techniques, spray coating techniques are often used and have advantages compared to other techniques, namely a highly homogeneous surface is produced, so that this method can prevent excessive porosity. The resulting resistance and transmittance are $10 \Omega . \mathrm{sq}^{-1}$ and $87.4 \%$ [22-24]. AgNWs film making by the spray coating method depends on the nozzle speed, diameter, and length of AgNWs. The higher the nozzle speed, the higher the values of transmittance and resistance because the total number of AgNWs coming out decreases [25] and causes the AgNWs to be less dense [26]. High resistance can be overcome by using a larger diameter and length of AgNWs so that the resistance is lower and the transmittance is higher [27].

Based on these factors, a thin layer of AgNWs will be made using a spray coating technique and varying the number of layers. The resulting layer will be characterized with an ultraviolet-visible (UVVis) spectrophotometer to determine its optical properties, four-point probe (FPP) to determine its electrical properties, and the characterization of scanning electron microscopy (SEM) to determine the surface structure and thickness of the AgNWs layer.

\section{Materials and methods}

The materials used in this study include $\mathrm{AgNO}_{3}$ (Sigma Aldrich), polyvinyl pyrolidone (PVP, Mw. 30K, Namhang Industrial), ethylene glycol (Citra Sari Kimia, Indonesia), $\mathrm{FeCl}_{3} \cdot 6 \mathrm{H}_{2} \mathrm{O}$, ethanol (Erkamed Alcohol 96\%), aquadest, and substrate polycarbonate. The tools used in this study include a hot plate stirrer (Diab MS-H280-Pro), thermocouple (Lutron TM-902), ultrasonic cleaner (Delta D68H, Taiwan), compressors (Fini air compressore, Pioneer), ovens (Kirin), centrifuge (800D Centrifuge), and spray equipment (Air Brush Kit with a capacity of $7 \mathrm{cc}$, nozzle diameter $0.2 \mathrm{~mm}$ ). Schematic synthesis of AgNWs as shown in Figure 1. 


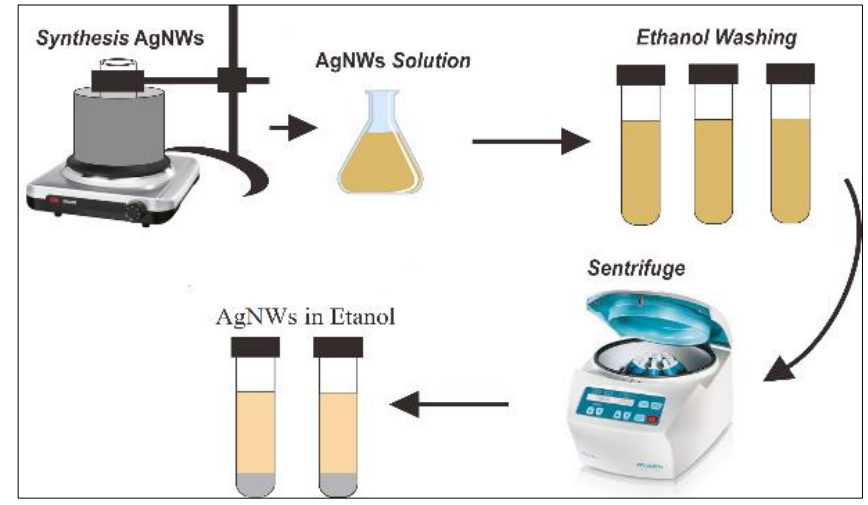

Figure 1. Synthesis of silver nanowires

AgNWs were obtained using the polyol method, with PVP as a reducing agent and ethylene glycol (EG) as a solvent. Firstly, PVP powder was dissolved with $30 \mathrm{~mL}$ EG with a concentration of $0.45 \mathrm{M}$ using a hotplate stirrer at $130^{\circ} \mathrm{C}$ and $350 \mathrm{rpm}$ for $1 \mathrm{~h}$. Next, the amount of $\mathrm{FeCl}_{3} \cdot 6 \mathrm{H}_{2} \mathrm{O} 100 \mu \mathrm{L}$ with a concentration of $0.04 \mathrm{M}$ and $12 \mathrm{~mL}$ of $\mathrm{AgNO}_{3}$ with a concentration of $0.5 \mathrm{M}$ added dropwise for 1 hour. All solutions were then sterilized for $2 \mathrm{~h}$. After $2 \mathrm{~h}$, the AgNWs solution was cooled to room temperature for $30 \mathrm{~min}$. Next, AgNWs were washed, using ethanol, by pouring AgNWs solution into an autoclave tube and adding ethanol, then centrifuging for five minutes at a speed of $3000 \mathrm{rpm}$ three times. Deposits of AgNWs formed are transferred to the auto clap for further processing [17].

The manufacture of AgNWs thin films is carried out using a spray coating technique with variations in the number of layers (1-3 layers) on a polycarbonate substrate by spray coating. Figure 2 illustrates the technique for making AgNWs thin films by spray coating.

At this stage, it is carried out by pouring a coating agent in the form of AgNWs solution with a concentration of $10 \%$ into a container, which is in the spray device as the source of the coating. After that, the spray tool is connected with the compressor, which applies air pressure to the spray device so that the solution can be spread on the substrate. A copper tube is wrapped around the compressor hose's hot element which aims to flow air pressure in the form of steam. The copper tube is heated to $60{ }^{\circ} \mathrm{C}$ using a hot plate.

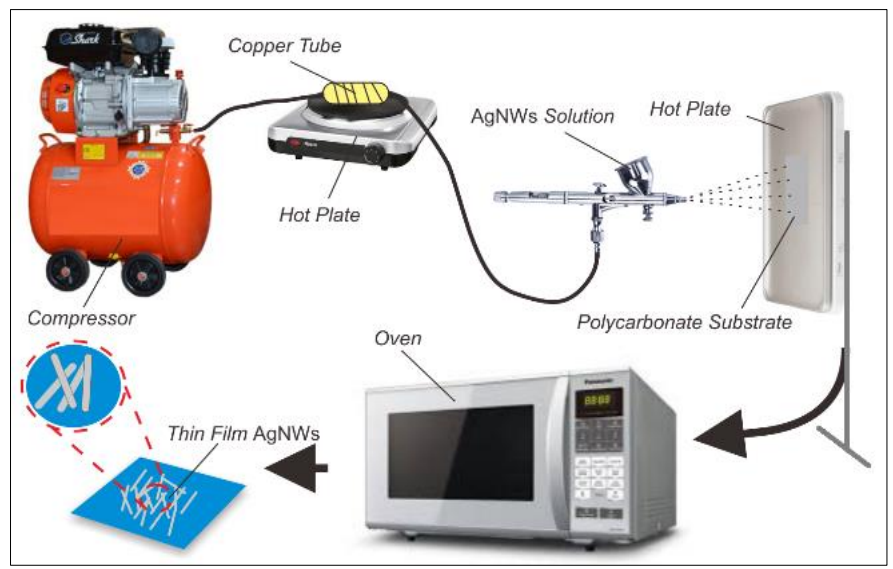

Figure 2. Deposition of AgNWs films by spray coating

Five $\mathrm{ml}$ of coating material used for 1 layer. At the time of spraying, the substrate while heated on a hot plate with a temperature of $90^{\circ} \mathrm{C}$, a pressure of 1-1.5 bar, and the distance of the spray nozzle to the substrate is $10 \mathrm{~cm}$. Spraying is done until the coating material is used up and spread evenly on the substrate. After the coating material is spread evenly, the layers are drained in an oven at $90^{\circ} \mathrm{C}$ for 15 minutes. For the next coating, the coated AgNWs layer is then resurfaced using the same technique. 
For characterization, UV-vis spectrometer (Shimadzu, UV-1700) was used to measure the absorption and transmission spectrum of AgNWs films in the 300 to $700 \mathrm{~nm}$ wavelength range. The electrical properties of AgNWs films were measured using a four-point probe (VEECO FPP-5000). Furthermore, the morphology, size, and thickness of AgNWs solution and AgNWs films were observed using scanning electron microscopy (JEOL, JSM-6510) by accelerating voltage of $10 \mathrm{kV}$.

\section{Results and discussions}

The coating material used is AgNWs solution with a concentration of $10 \%$ in ethanol, which has a diameter and length of AgNWs of $176.13 \mathrm{~nm}$ and $28.58 \mu \mathrm{m}$, respectively. Figure 3 shows the results of measurement of transmittance of AgNWs layers using a UV-vis spectrometer.

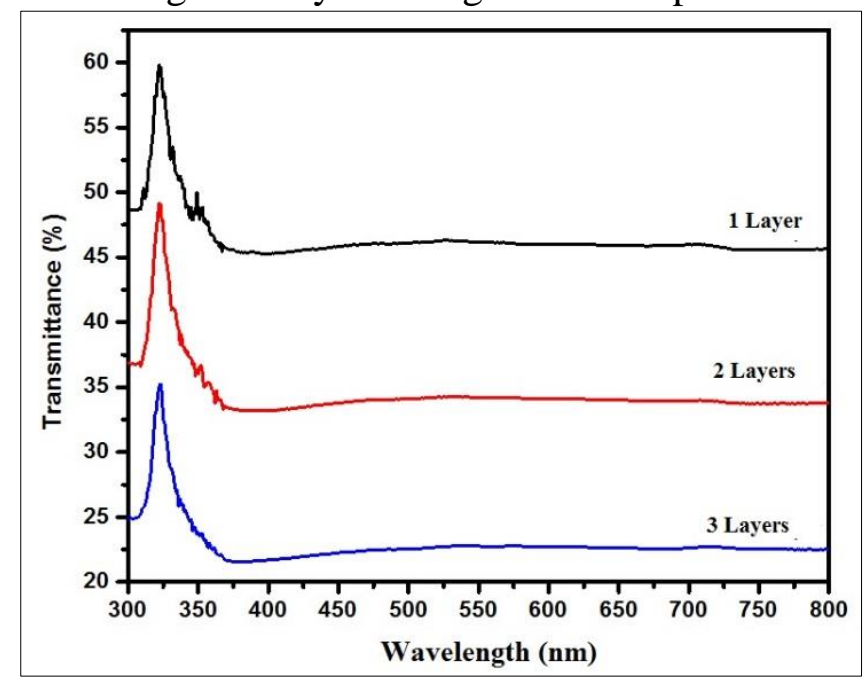

Figure 3. UV-vis spectra of transmittance AgNWs thin films

The transmittance is the ratio between the intensity of light entering the AgNWs layer with the intensity of light going out of the AgNWs layer. Transmittance will always be raised in the form of a percentage at a specific wavelength of $550 \mathrm{~nm}$. The transmittance of the AgNWs layer, according to Eda et al. can be seen at a wavelength of $550 \mathrm{~nm}$ [4].

At a wavelength of $550 \mathrm{~nm}$, the transmittance of thin layers of AgNWs with variations of 1, 2, and 3 layers is $46.16 \% ; 34.20 \%$; and $23.81 \%$, respectively. The results obtained show that the higher the number of layers, the smaller the transmittance [14,19]. Lambert-Beer's Law states that the transmittance and absorbance relationship is inversely proportional [28]. The absorbance results of AgNWs thin films can be seen in Figure 4.

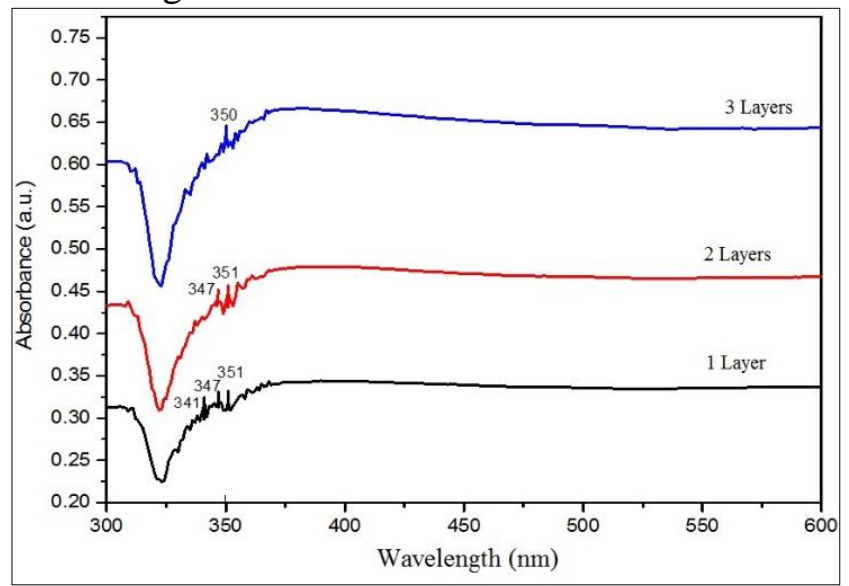

Figure 4. UV-vis spectra of absorbanceAgNWs thin films 
Absorbance is the amount of light or energy that the thin film material absorbs from the total light emitted. The absorbance peak at a $340 \mathrm{~nm}$ wavelength indicates that $\mathrm{Ag}$ consists of a mixture of nanoparticles (NP), nanorod (NRd), and NWs [29,30]. The absorbance peak around $350 \mathrm{~nm}$ indicates the presence of $\mathrm{Ag}$ in the form of NWs. The absence of absorption peaks around $410 \mathrm{~nm}$ indicates that there is no silver element [31,32].

In Figure 4, the graph illustrates the absorbance results of AgNWs thin films with variations in 1, 2, and 3 layers. In one layer, there are three absorbance peaks, namely at wavelengths of $341 \mathrm{~nm}, 347 \mathrm{~nm}$ and $351 \mathrm{~nm}$ with absorbance peaks of $0.32 ; 0.32$; and 0.32 . One layer shows that there is still $\mathrm{Ag}$ in the form of nanoparticles, small spheres, NRs, and NWs.

There are two absorbance peaks in the two layers, namely at wavelengths of $347 \mathrm{~nm}$ and $351 \mathrm{~nm}$, with absorbance peaks of 0.44 and 0.45 , respectively. The absorption peak of $347 \mathrm{~nm}$ shows that there is still $\mathrm{Ag}$ in the form of nanoparticles, small spheres, NRs, and NWs. The absorption peak of $351 \mathrm{~nm}$ indicates that $\mathrm{Ag}$ has the form of NWs.

In the three layers, there is one absorbance peak at a wavelength of $350 \mathrm{~nm}$ with an absorbance peak of 0.64. The absorption peak of $350 \mathrm{~nm}$ corresponds to the presence of Ag in the form of NWs. These results confirm the presence of silver with excellent aspects [31,32]

As the number of layers increases, an increase in absorption peaks and a decrease in transmittance occur. This proves the statement of Skoog and Leary that transmittance and absorbance are inversely proportional [28]. From the results of transmittance and absorbance, reflectance value and absorbance coefficient will be known, then the refractive index value, optical conductivity, and energy gap will be produced [17].

The index of refraction occurs when light propagates in material; its speed will decrease by a factor determined by the material's characteristics. The refractive index is also a ratio of the speed of light in a vacuum to the speed of light in a material. When light passes through two different media with optical density, the light propagation direction in the second medium will be deflected. The results of the AgNWs thin film refractive index are in Figure 5.

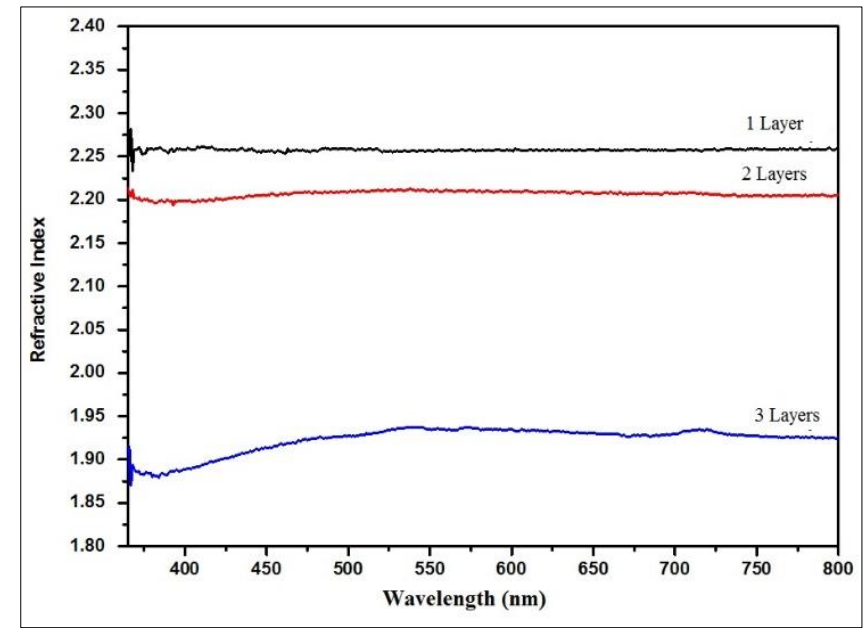

Figure 5. The refractive index of AgNWs thin films with variations in the number of layers

The refractive index value is calculated using the reflectance value and the layer's absorbance coefficient. The refractive index of the AgNWs layer can be seen at a wavelength of $550 \mathrm{~nm}$. The refractive index of AgNWs layers with variations of 1, 2, and 3 layers in a row is 2.26, 2.21, and 1.93. As the number of layers increases, the resulting refractive index decreases. The resulting refractive index of thin films is in accordance with the literature, which is 1.5 to $3.5[33,34]$. 


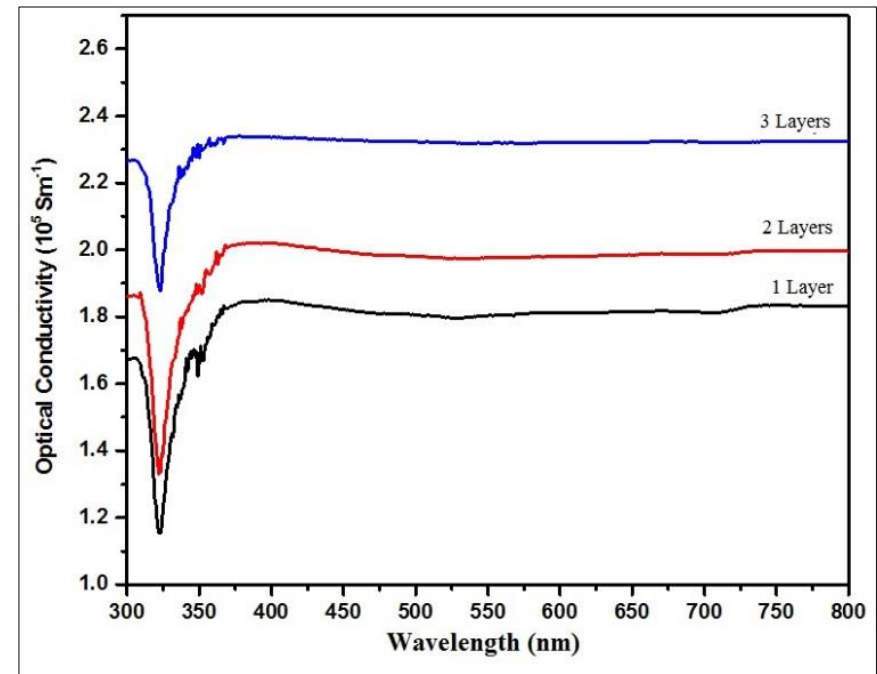

Figure 6. The optical conductivity of AgNWs thin films with variations in the number of layers

The refractive index will affect the density of AgNWs in the layer because pores form on the surface [33]. The smaller the refractive index value, the AgNWs density value increases and the smaller the pore size. The refractive index value can be used to calculate the optical conductivity of AgNWs thin films, as shown in Figure 6.

Optical conductivity is measured by the reflectance of the sample. To measure optical conductivity, measurements are combined with static limits on the wave frequency. Optical conductivity is seen at a wavelength of $550 \mathrm{~nm}$. Optical conductivity produced at 1,2 , and 3 layers were $1.80 \times 10^{5} \mathrm{~S}^{-\mathrm{m}^{-1}}, 1.98$ $\times 10^{5} \mathrm{~S} . \mathrm{m}^{-1}$, and $2.32 \times 10^{5} \mathrm{~S} . \mathrm{m}^{-1}$. The optical conductivity produced is lower than the metallic silver conductivity of $6.3 \times 10^{7} \mathrm{~S} . \mathrm{m}^{-1}$ [35].

The greater the number of layers, the higher the optical conductivity. When associated with the refractive index results, the greater the number of layers, the higher the optical conductivity, and the lower the refractive index. This shows that the optical conductivity value is inversely proportional to the layer's refractive index. Optical conductivity will affect the energy gap produced. The energy gap generated from AgNW thin films is shown in Figure 7.

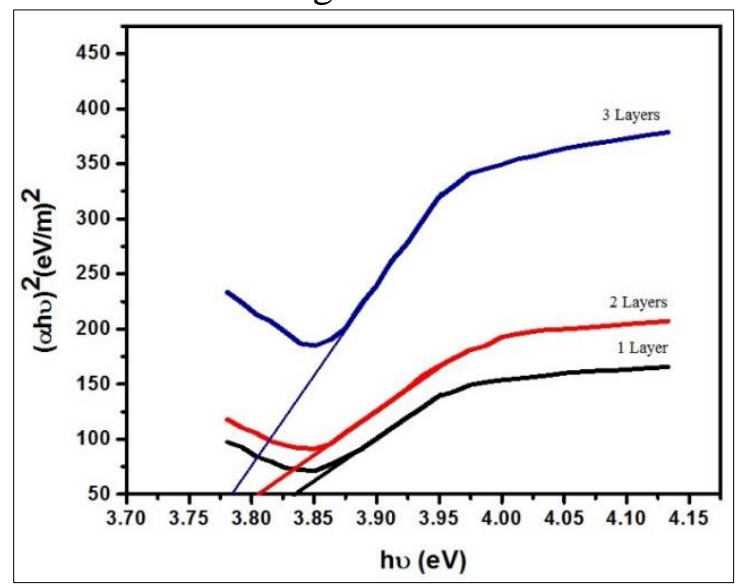

Figure 7. The bandgap energy of AgNWs thin films with variations in the number of layers

The energy gap is the energy needed by electrons to be able to move from the valence band to the conduction band. The energy gap is determined using the Tauc plot method and applied to semiconductor materials. The method of Tauc plot (with value $n=1 / 2$ ) can be carried out by graphing the relationship between $(\alpha h v)^{2}$ to $h v$, then performing linear extrapolation $(\alpha h v)^{2}$ to $h v$ cutting the $\mathrm{x}$ - 
axis (abscissa) [36]. Linear extrapolation, which cuts the abscissa, is the energy gap value. The value of $n$ that is used is $n=1 / 2$ indicates an indirect transition [36].

AgNWs thin films with variations of 1, 2, and 3 layers produce gap energy of $3.84 \mathrm{eV}, 3.81 \mathrm{eV}$, and $3.79 \mathrm{eV}$, respectively. The gap energy value corresponds to the gap energy $\mathrm{Ag}$, which is 3.1 to 5.2 $\mathrm{eV}$ [37]. The energy gap of the AgNWs layer is almost the same as ITO of $3.8 \mathrm{eV}$ [38]. The gap energy produced is getting smaller as the number of layers increases. The smaller energy gap indicates that more energy is absorbed by the material, so the absorbance value is higher. These conditions are in accordance with the absorbance results obtained, as shown in Figure 4. The smaller the energy gap, the greater the optical conductivity. Greater optical conductivity produces a good performance as a transparent electrode [39].

In general, the gap energy of semiconductor material is below $6 \mathrm{eV}$. The FPP test results show that the semiconductor produced is p-type and n-type semiconductors. This semiconductor is a type of extrinsic semiconductor, which is impure because it is polluted by other types of atoms. The process of adding impurity atoms to pure semiconductors is called doping. By adding impurities (impurities), the band structure and resistivity will change.

Total electrical resistivity ( $\left.\rho_{\text {total }}\right)$ on nanomaterial materials is the sum of individual electrical resistivity $\left(\rho_{0}\right)$ due to crystal defects or impurity scattering, Bloch-Gruneisen resistivity $\left(\rho_{L}\right)$ and Kondo resistivity $\left(\rho_{\text {spin }}\right)$ as shown in Equation 1.

$$
\rho_{\text {total }}(T)=\rho_{0}+\rho_{L}(T)+\int_{T}^{\infty} \rho_{1} f\left(T_{k}\right) d T_{k}-\int_{T}^{\infty} \rho_{2}|J| \ln (T) f\left(T_{k}\right) d T_{k}
$$

where $f\left(T_{k}\right)$ is a particle size distribution function. Bloch-Gruneisen resistivity is phonon resistivity. Phonon contributes to thermal and electrical conductivity; if there are no phonons, then all materials will become insulators [40]. Kondo resistivity occurs because of the Kondo effect. The Kondo effect describes conduction electrons in metals due to magnetic impurities, resulting in characteristic electrical resistivity changes [41-42].

In ordinary silver wire room temperature conditions, phonon-electron scattering is dominant, but for silver NWs, both phonon scattering and structural scattering contribute to the overall electrical resistivity magnitude. This also occurs because of the silver NWs thinning process, or the process of depleting the size of the NWs, so that the resistance of silver in the form of NWs is five times greater than silver in the form of overflow [43]. This makes the NWs silver conductivity much smaller than the usual silver conductivity, as shown in Figure 6.

The greater the number of layers, the smaller the gap energy. The smaller the energy gap, the greater the optical conductivity. Higher optical conductivity results in a good performance as a transparent electrode [37]. The greater the optical conductivity, the smaller the resistance [17]. The results of AgNWs thin film resistance can be seen in Figure 8. The resistance of AgNWs thin films for 1,2 , and 3 layers were $26,30 \Omega, 4.67 \Omega$, and $1.10 \Omega$, respectively.

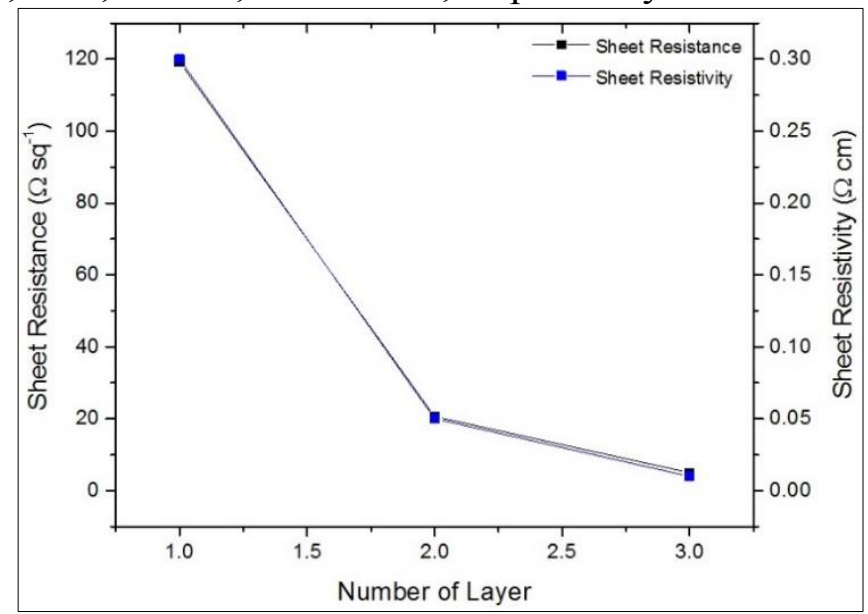

Figure 8. Resistance and resistivity of AgNWs thin films 
The results of resistance and resistivity of AgNWs thin films have the same ratio. Thin-film resistance in variations of 1 to 3 layers was $119.2 \Omega . \mathrm{sq}^{-1}, 20.6 \Omega . \mathrm{sq}^{-1}$ and $4.98 \Omega . \mathrm{sq}^{-1}$. The best resistance value results in variations of 3 layers. The resistance value produced in this study is lower than the resistance value obtained by Lee et al. with a resistance of $16 \Omega . \mathrm{sq}^{-1}$ in 3 layers [13]. The resistivity of AgNWs thin films for 1,2 and 3 layers were $0.30 \Omega . \mathrm{cm}, 0.05 \Omega . \mathrm{cm}$ and $0.01 \Omega . \mathrm{cm}$, respectively. The greater the number of layers, the lower the resistance and resistivity of the layer, which causes higher conductivity. The best resistance and resistivity are found in variations of 3 layers.

The lower layer resistance will affect the density of AgNWs on the layer's surface. The lower the layer resistance, the higher the density of AgNWs and the greater the thickness of the layer [26]. This can be proven by SEM results shown in Figure 9 and Figure 10.

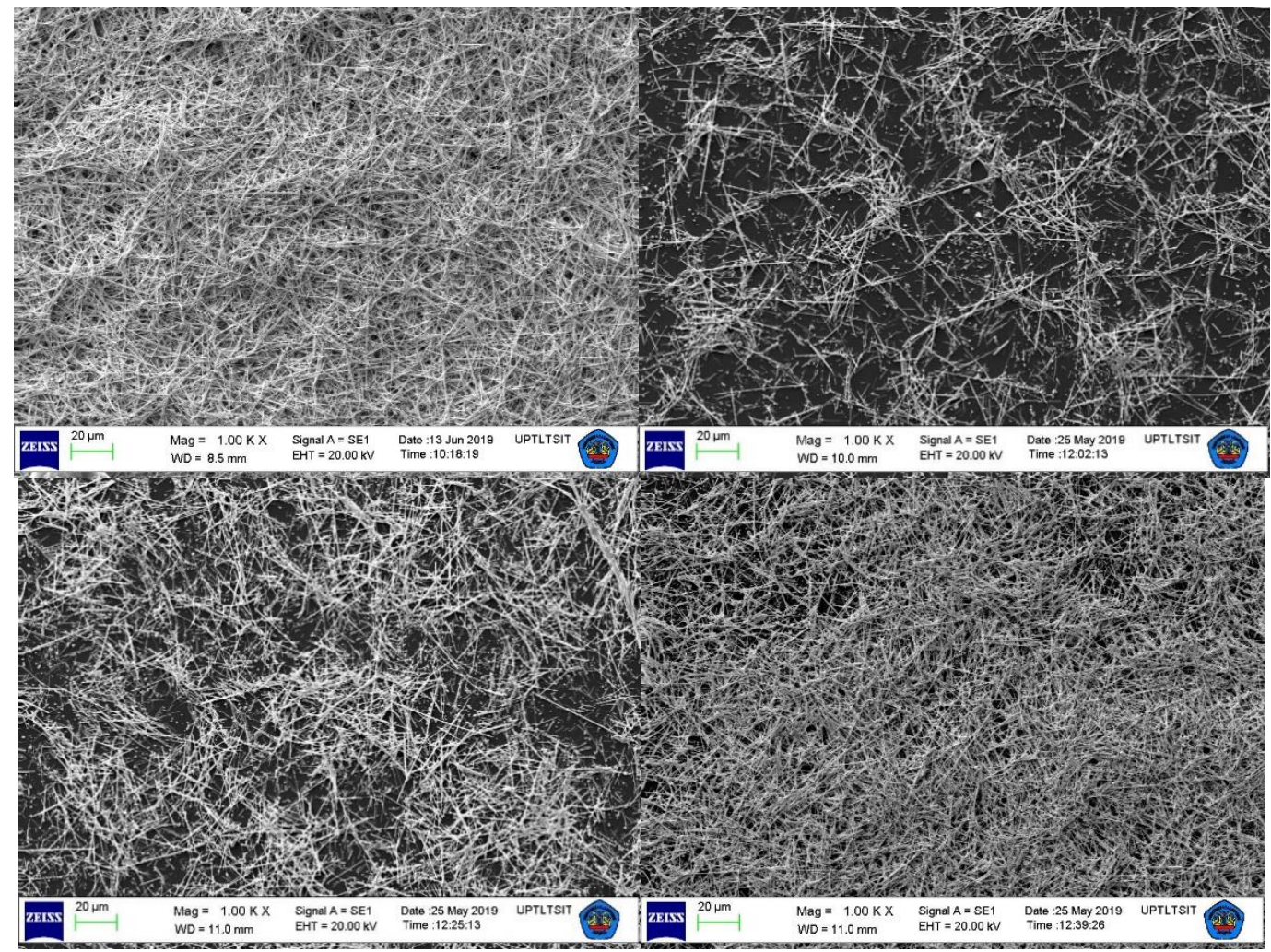

Figure 9. SEM images of (a) $10 \% \mathrm{AgNW}$ s solution, AgNWs thin films for

(b) 1 layer, (c) 2 layers, and (d) 3 layers

The SEM results were identified by the diameter and length of AgNWs by using ImageJ. Based on SEM results when viewed visually, the AgNWs layer variations 1, 2, and 3 layers have different AgNWs densities (in terms of the number of AgNWs) on the layer surface. Increasing the density of AgNWs on the layer surface will reduce the layer's resistance and transmittance [39]. The increasing refractive index will increase the value of AgNWs density on the layer's surface because the surface pores' sizes are getting smaller [33]. AgNWs layers, with variations of 1, 2, and 3 layers, have successive pore sizes of $(13.2 \pm 7.0) \mu \mathrm{m},(7.4 \pm 3.4) \mu \mathrm{m}$, and $(2.8 \pm 1.2) \mu \mathrm{m}$. The greater the number of $\mathrm{AgNWs}$ layers, the smaller the pore size of AgNWs and the greater the AgNWs density. The smaller the pore size, the higher the level of homogeneity, so that surface roughness and resistance will decrease [13].

Figure 10 shows that the AgNWs layer thickness for 1 layer was $44.244 \mu \mathrm{m}$. In Figure 10(b), the thickness of the AgNWs layer, with a variation of 2 layers, has a layer thickness of $69.126 \mu \mathrm{m}$. In Figure 10(c), the thickness of the AgNWs layer with a variation of 3 layers has a layer thickness of 
$100,028 \mu \mathrm{m}$. Based on the results obtained, the greater the number of layers, the greater the layer thickness. Layer thickness increases, resulting in lower transmittance and resistance.

The resulting AgNWs layer has several problems, namely instability of AgNWs and weak adhesion. AgNWs instability occurs when temperatures above $100^{\circ} \mathrm{C}$, where the deformed layer becomes harder and the resistance of the layer is very high. This happens because AgNWs are melting and causes the AgNWs network to become thinner [26]. As the temperature continues to rise, AgNWs begin to break and produce intermittent AgNWs, thereby increasing tissue sheet resistance to $\mathrm{k} \Omega$ and $\mathrm{M} \Omega$. According to Khalig and Goldthorpe, when temperatures above $200^{\circ} \mathrm{C}$ NWs turned into a spherical shape [44].
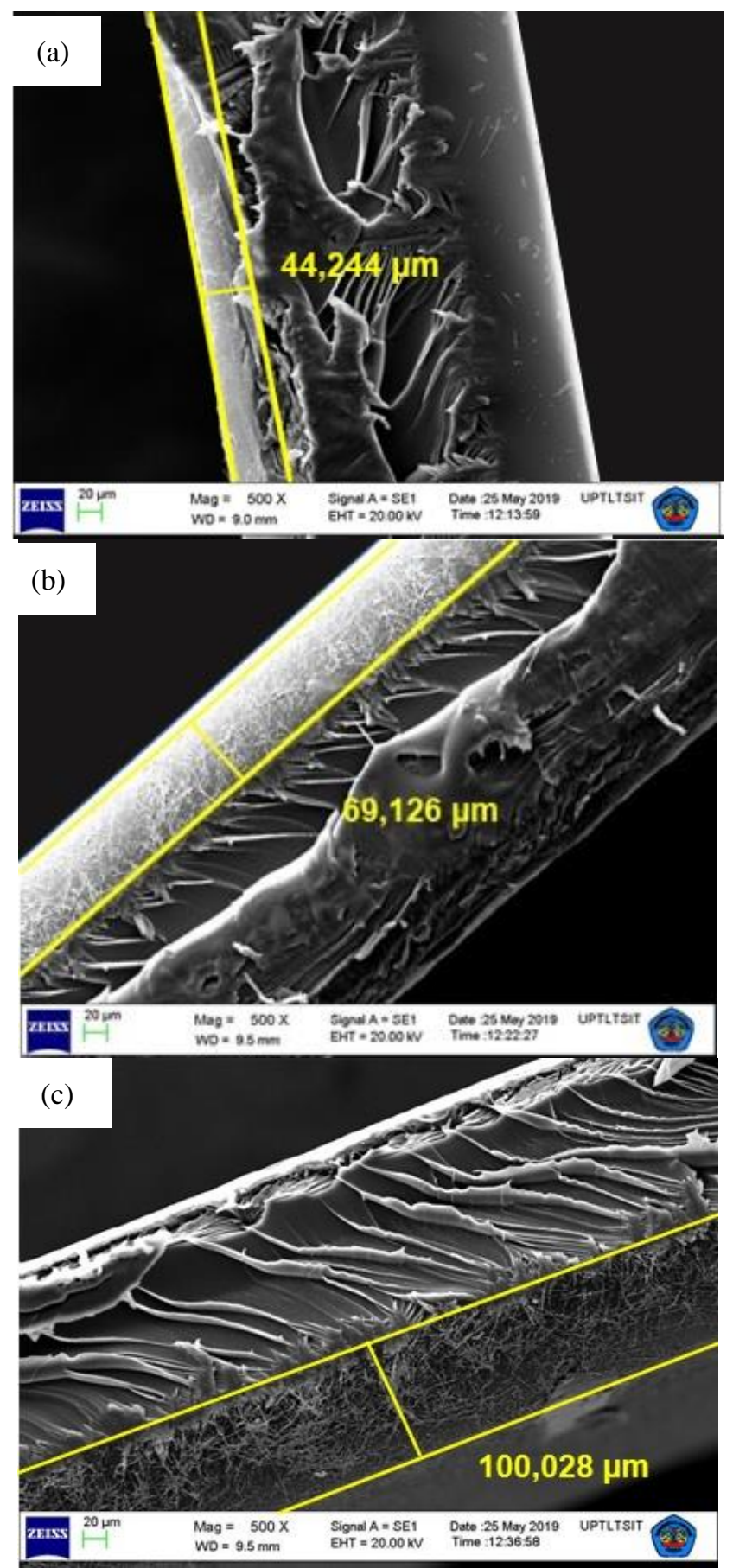

Figure 10. Cross section SEM image of AgNWs

layer thickness for (a) 1 Layer, (b) 2 layers, and (c) 3 layers

The resulting AgNWs layer is easily scratched so that it can remove NWs on the surface. When AgNWs are easily scratched, resulting in weaker adhesion [12]. The proposed method for increasing 
adhesion is to add an additional layer above the AgNWs layer, so as to reduce surface roughness and drastically increase NWs adhesion [45].

Based on research, increasing the number of layers increases absorbance and decreases transmittance. More and more AgNWs will increase the density of AgNWs on the layer surface. Increased density of $\mathrm{AgNWs}$ on the layer surface causes the layer thickness to increase, the layer resistance to decrease, and optical conductivity to increase. As optical conductivity increases, the gap energy produced decreases. Optical resistance and conductivity were obtained at $4.98 \Omega . \mathrm{sq}^{-1}$ and 2.32 $\times 10^{5} \mathrm{~S} . \mathrm{m}^{-1}$, respectively.

\section{Conclusions}

The effect of variations in the number of AgNWs thin films, using spray coating techniques, shows that the greater the number of layers, the higher the transmittance and the lower the resistance. Conversely, optical conductivity and coating thickness increases. The transmittance of AgNWs thin films with variations in 1 to 3 layers was $46.16 \%$; $34.20 \%$; and $23.81 \%$. The results of transmittance are inversely proportional to the absorbance, where the smaller the value of transmittance, the greater the value of absorbance. The best absorbance peak is in the variation of 3 layers at a wavelength of 350 $\mathrm{nm}$, which indicates the presence of AgNWs. The resulting resistances in AgNWs thin films, with variations of 1,2 , and 3 layers, were $119.2 \Omega . \mathrm{sq}^{-1}, 20.6 \Omega . \mathrm{sq}^{-1}$ and $4.98 \Omega . \mathrm{sq}^{-1}$, respectively,. The resistance values in the 2 and 3 layer variations correspond to the ITO resistance values. On the surface morphology results, the AgNWs length deformation occurred between 10\% AgNWs solution and AgNWs thin films obtained by $44.244 \mu \mathrm{m}, 69.126 \mu \mathrm{m}$, and $100.028 \mu \mathrm{m}$ for each layer.

Acknowledgements: This work was supported by a research grant of Profesorship, Contract No. 1516/UN26.21/PN/2020 by Ministry of Research, Technology and Higher Education of the Republic of Indonesia via Institute for Research and Community Services of Universitas Lampung. The authors would like to thank Enago (www.enago.com) for the English language proofread and review.

\section{References}

1.JIANG, J., WONG, F., FUNG, M., LEE, S., Aluminium doped zinc oxide films as a transparent conducting electrode for organic light emitting devices, Optoelectron. Adv. Mater. Rapid Commun., 83, 2003, 1875-1877.

2.JOHAN, M.R., AZRI, N., AZNAN, K., YEE, S.T., HO, I.H., OOI, S.W., Synthesis and Growth Mechanism of Silver Nanowires through Different Mediated Agents $\left(\mathrm{CuCl}_{2}\right.$ and $\left.\mathrm{NaCl}\right)$ Polyol Process, Nanomaterials, 2014, 2014, 1-7.

3.ELLMER, K., Past Achievements and Future Challengges in the Development of Optically Transparent Electrodes, Nat. Photonics, 6, 2012, 809-817.

4.EDA, G., LIN, Y., MILLER, S., CHEN, C., SU, W., Transparent and Conducting Electrodes for Organic Electronics from Reduced Graphene Oxide, Appl. Phys. Lett., 33305, 2008, 1-4.

5.MINAMI, T., Present Status of Transparent Conducting Oxide Thin-Film Development for IndiumTin-Oxide (ITO) Substitutes, Thin Solid Films, 516, 2008, 5822-5828.

6.KIM, T., CANLIER, A., KIM, G.H., CHOI, J., PARK, M., HAN, S.M., Electrostatic Spray Deposition of Highly Transparent Silver Nanowire Electrode on Flexible Substrate Electrostatic Spray Deposition of Highly Transparent Silver Nanowire Electrode on Flexible Substrate, ACS Appl. Mater. Interfaces, 1155, 2013, 1-24.

7.HECHT, D.S., HU, L., IRVIN, G., Emerging Transparent Electrodes Based on Thin Films of Carbon Nanotubes , Graphene, and Metallic Nanostructures, Adv. Mater., 23, 2011, 1482-1513.

8.WANG, J., JIU, J., NOGI, M., SUGAHARA, T., NAGAO, S., KOGA, H., A highly sensitive and flexible pressure sensor with electrodes and elastomeric interlayer containing silver nanowires, Nanoscale, 7, 2015, 2926-2932.

9.KHALIGH, H.H., Silver Nanowire Transparent Electrodes for liquid crystal-based smart windows, 
Sol. Energ. Mat. Sol. C., 132, 2016, 337-341.

10.YOON, B.Y., SONG, J., KIM, D., KIM, J., PARK, J., OH, S., Transparent Film Heater Using Single-Walled Carbon Nanotubes, Adv. Mater., 19, 2007, 4284-4287.

11.BAE, S., KIM, H., LEE, Y., XU, X., PARK, J.S., ZHENG, Y., Roll-to-Roll Production of 30-Inch Graphene Films for Transparent Electrodes, Nat. Nanotechnol., 5, 2010, 574-578.

12.LANGlEY, D., CELlE, C., BELlET, D., SIMONATO, J., Flexible Tansparent Conductive Materials Based on Silver Nanowire Networks : a Review, Nanotechnology, 24, 2013, 1-21.

13.LEE, J., SHIN, D., PARK, J., Fabrication of Silver Nanowire-Based Stretchable Electrodes Using Spray Coating, Thin Solid Films, 608, 2016, 34-43.

14.LEE, J., LEE, I., KIM, T., LEE, J., Efficient Welding of Silver Nanowire Networks without PostProcessing, Nanowire Networks, 9, 2013, 2887-2894.

15.HU, L., KIM, H.S., LEE, J.Y., PEUMANS, P., CUI, Y., Scalable Coating and Properties of Transparent, Flexible, Silver Nanowire Electrodes, ACS Nano, 4, 2010, 2955-2963.

16.RATHMELL, A.R., BERGIN, S.M., HUA, Y.L., LI, Z.Y., WILEY, B.J., The growth mechanism of copper nanowires and their properties in flexible, transparent conducting films, Adv. Mater., 22, 2010, 3558-3563.

17.JUNAIDI, TRIYANA, K., SUHARYADI, E., HARSOJO, WU, L.Y.L., The Roles of Polyvinyl Alcohol (PVA) as the Capping Agent on the Polyol Method for Synthesizing Silver Nanowires, $J$. Nano Res., 49, 2017, 174-180.

18.BERNAL, A.M., ARDILA, A.M., VEGA-VERDUGO, M., Fabrication and Study of Thin Transparent Conductive Films Prepared by Spin Coating from Metal Nano-wires, Mater. Sci., 132, 2016, 125-132.

19.AHN, K., KIM, D., KIM, O., NAM, J.. Analysis of Transparent Conductive Silver Nanowire Films from Dip Coating Flow, J. Coatings Technol. Res., 12, 2015, 855-862.

20.GAO, J., KEMPA, K., GIERSIG, M., AKINOGLU, E.M., HAN, B., LI, R., Physics of Transparent Conductors, Adv. Phys., 65, 2016, 553-617.

21.BID, A., BORA, A., RAYCHAUDHURI, A.K., Temperature Dependence of the Resistance of Metallic Nanowires of Diameter $\geq 15 \mathrm{~nm}$ : Applicability of Bloch-Grüneisen theorem, Phys. Rev. B Condens. Matter Mater. Phys., 74, 2006, 1-9.

22.LAGRANGE, M., LANGLEY, D., GIUSTI, G., JIMÉNEZ, C., BRECHET, Y., BELLET, D., Fluorescent Aliphatic Hyperbranched Polyether: chromophores-free and without any N and P Atoms, Phys. Chem. Chem. Phys., 7, 2016, 17410-17423.

23.CORCIOVA, A., BURLEC, A.F., GHELDIU, A.M., FIFERE, A., LUNGOCI, A.L., MARANGOCI, N., MIRCEA, C., Biosynthesis of Silver Nanoparticles Using Licorice Extract and Evaluation of their Antioxidant Activity, Rev. Chim., 70(11), 2019, 4053-4056.

24.SELZER, F., WEIß, N., KNEPPE, D., BORMANN, L., SACHSE, C., GAPONIK, N., A SprayCoating Process for Highly Conductive Silver Nanowire Networks as the Transparent Top-Electrode or Small Molecule Organic Photovoltaics, Nanoscale, 7, 2015, 2777-2783.

25.HAN, K., XIE, M., ZHANG, L., YAN, L., WEI, J., JI, G., Fully Solution Processed SemiTransparent Perovskite Solar Cells with Spray-Coated Silver Nanowires/ZnO Composite Top Electrode, Sol. Energy Mater. Sol. Cells, 185, 2018, 399-405.

26.ERGUN, O., COSKUN, S., YUSUFOGLU, Y., High-Performance , Bare Silver Nanowire Network Transparent Heaters, Nanotechnology, 27, 2016, 1-9.

27.ANDRÉS, J.L., MENÉNDEZ, M.F., GOMEZ, D., MARTÍNEZ, A.L., BRISTOW, N., KETTLE, J.P., MENÉNDEZ, A., RUIZ, B., Rapid Synthesis of Ultra-Long Silver Nanowires for Tailor-made Transparent Conductive Electrodes: Proof of Concept in Organic Solar Cells, Nanotechnology, 26, 2015, 1-9.

28.SKOOG, D., LEARY, J., Principles of Instrumental Analysis, 4th Edition, 1992, 1992, 224. 
29.TSUJI, M., NISHIZAWA, Y., MATSUMOTO, K., KUBOKAWA, M., MIYAMAE, N., TSUJI, T., Effects of Chain Length of Polyvinylpyrrolidone for the Synthesis of Silver Nanostructures by a Microwave-Polyol Method, Mater. Lett., 60, 2006, 834-838.

30.SUN, Y., GATES, B., MAYERS, B., XIA, Y., Crystalline Silver Nanowires by Soft Solution Processing, Nano Letters, 2002, 2002, 1-4.

31.LUNGULESCU, E.M., SBARCEA, G., SETNESCU, R., NICULA, N., DUCU, R., LUPU (LUCHIAN), A.M., ION, I., MARINESCU, V., Gamma Radiation Synthesis of Colloidal Silver Nanoparticles, Rev. Chim., 70(8), 2019, 2826-2850.

32.FRIEDLER, I., LALANNE, P., HUGONIN, J. P., CLAUDON, J., GÉRARD, J.M., BEVERATOS, A., Efficient Photonic Mirrors for Semiconductor Nanowires, Opt. Lett., 33, 2008, 2635.

33.BUMBAC, M., OLTEANU, R.L., ION, R.M., NICOLESCU, C.M., Influence of Temperature on the Growth of Silver Nanoparticles Synthesized Using Salvia officinalis Aqueous Extract, Rev. Chim., 69(8), 2018, 1934-1938.

34.DE, S., HINGGGINS, H.M., LYON, P.E., DOHERTY, E.M., NIRMALRAJ, P.N., LOVRICS, S., Silver Nanowire Networks as Flexible, Transparent, Conducting Films: Extremely High DC to Optical Conductivity Ratios, Am. Chem. Soc., 3, 2009, 1767-1774.

35.MI, H.Y., LI, Z., TURNG, L.S., SUN, Y., GONG, S., Silver Nanowire/Thermoplastic Polyurethane Elastomer Nanocomposites: Thermal, Mechanical, and Dielectric Properties, Mater. Des., 56, 2014, 398-404.

36.OLTEANU, R.L., NICOLESCU, C.M., BUMBAC, M., DULAMA, I.D., ION, R.M., BUNGHEZ, I.R.S., Study on Critical Micelle Concentration Influence in Green Synthesis of Silver Nanoparticles Assisted by Sapindus mukorossi Aqueous Extract, Rev. Chim., 69(6), 2018, 1339-1345.

37.GINLEY, D.S., HOSONO, H., PAINE, D.C., Handbook of Transparent Conductors, 2010, pp. 1527.

38.DE, S., COLEMAN, J.N., The Effects of Percolation in Nanostructured Transparent Conductors, MRS Bull., 36, 1969, 774-781.

39.KONDO, J., Theory of dilute magnetic alloys, Solid State Phys., 23, 1969, 184-281.

40.MATULA, R.A., Electrical Resistivity of Copper, Gold, Palladium, and Silver, J. Phys. Chem. Ref. Data, 8, 1979, 1147-1298.

41.AL-JALALI, M.A., MOUHAMMAD, S.A., Phonons Bloch-GrÜNeisen Function and Its Applications To Noble Metals Resistivity, Part I, Int. J. Pure Appl Math., 102, 2016, 233-245.

42.HEWSON, A.C., KONDO, J., Efek Kondo, Scholarpedia. 2009, 2009, 7529.

43.CHENG, Z., LIU, L., XU, S., LU, M., WANG, X., Temperature Dependence of Electrical and Thermal Conduction in Single Silver Nanowire, Sci. Rep., 5, 2015, 1-12.

44.KHALIGH, H.H., GOLDTHORPE, I.A., Failure of silver nanowire transparent electrodes under current flow, Nanoscale Res. Lett., 8, 2013, 2-7.

45.MILlER, M.S., O'KANE, J.C., NIEC, A., CARMICHAEL, R.S., CARMICHAEL, T.B., Silver Nanowire/Optical Adhesive Coatings as Transparent Electrodes for Flexible Electronics, ACS Appl. Mater. Interfaces, 5, 2013, 10165-10172.

Manuscrupt received: 27.03.2020 